\title{
Comunicação científica em saúde no Brasil: revisão de literatura
}

\section{Scientific communication about health in Brazil: a literature review}

\author{
Maria de Fátima Mendes Martinelli ${ }^{1}$ \\ Carmen Fontes Teixeira ${ }^{2}$
}

\begin{abstract}
Resumo
Este trabalho trata do surgimento da comunicação científica em saúde no Brasil e dos primeiros periódicos científicos publicados no país, no século XIX. A metodologia utilizada foi a revisão exploratória de literatura, que implicou na busca sistemática de artigos científicos registrados na SciELO, sendo encontrados 49 trabalhos, no período de 1998 a 2012. Das principais questões abordadas, destacase a utilização de recursos eletrônicos para a difusão do conhecimento científico. Dos resumos analisados, foram selecionados os artigos que abordavam aspectos históricos, e que traziam informações sobre o surgimento e o desenvolvimento da comunicação científica no Brasil, no século XIX. Os resultados confirmam que o periódico científico é o veículo de comunicação, para a área da saúde, que mais contribui para o avanço da ciência. Destaca-se a importância da "Gazeta Médica da Bahia" como um periódico que participou do início da construção da comunicação científica no país e que permaneceu com publicação regular até 2012.
\end{abstract}

Palavras-chave: Comunicação Científica. Comunicação Científica no Brasil. Periódicos Científicos Brasileiros. Avaliação de Artigos Científicos.

\section{Abstract}

This work is about the emergent of scientific communication about health in Brazil and shows which were the scientific journals published in this country in $19^{\text {th }}$ century. The methodology utilized was the exploratory literature review that implicated in a systematic search for scientific articles registered in SciELO, and 49 works were founded in the period of 1998 to 2012. From the analyzed abstracts, the articles that have historic aspects and bring information about the emergent and the development of scientific communication in Brazil in $19^{\text {th }}$ century were selected. The results confirm that the scientific journals are the communication vehicle to health's field that most contribute to science advancement. It distinguishes the importance of the "Gazeta Médica da Bahia" as a periodic that had participated of the beginning of the scientific communication in the country and continues with regular publication until 2012.

Keywords: Scientific Communication. Scientific Communication in Brazil. Brazilian Scientific Periodicals. Scientific Article Evaluation.

\footnotetext{
1 Universidade Federal da Bahia. Bibliotecária na Biblioteca Universitária de Saúde na UFBA, mestranda na UFBA/IHAC. E-mail: mafatimendes@gmail.com.

${ }_{2}$ Universidade Federal da Bahia. Professora do Programa de Pós-Graduação em Estudos Interdisciplinares sobre Universidade do IHAC-UFBA e do Programa de Pós-graduação do Instituto de Saúde Coletiva - ISC-UFBA. E-mail: carment@ufba.br.
}

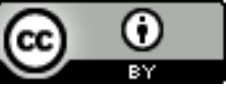




\section{Introdução}

A comunicação científica pode ser definida como um veículo de transmissão do conhecimento científico. Segundo Cortês (2006, p. 35), entendê-la, desde os seus primórdios até a utilização de meios eletrônicos, é um desafio. Weitzel (2006, p. 83) relata que a comunicação científica existe desde a antiguidade, na época em que os filósofos estabeleciam seus debates na Academia. Mas, é a partir do século $\mathrm{XVI}$, com as descobertas científicas, que há a expansão do conhecimento e o surgimento do periódico científico, o qual está associado a esses acontecimentos, e nasceu da necessidade dos cientistas se comunicarem com rapidez e de forma sistematizada. Packer e Meneghini (2006, p. 237) observam que a realização de pesquisas científicas e sua comunicação em periódicos se constituem na forma mais utilizada pelos pesquisadores, para divulgar e tornar visíveis os seus trabalhos.

O tema comunicação cientifica está estreitamente ligado à informação e à comunicação. No entanto, Targino (2000, p. 34) diz ser insensato restringir a comunicação à mera troca de informações entre cientistas, pois a ciência, como sistema social, integra elementos que vão desde a figura do pesquisador, do cientista e do acadêmico, ao fluxo de ideias, teorias, métodos, literatura científica e instrumentos, que permitem a operacionalização das investigações.

De acordo com Weitzel (2006, p. 83), a comunicação científica pode ser entendida como um processo que envolve a construção, a comunicação e o uso do conhecimento científico para promover sua evolução. Alguns aspectos favorecem a expansão e a acumulação do conhecimento, e, consequentemente, o aparecimento do trabalho científico. São eles: a laicização do conhecimento, com o fim do monopólio do saber controlado pela igreja católica e o domínio da imprensa e do papel; o desenvolvimento do método científico e das descobertas científicas; o surgimento das sociedades científicas, notadamente a Royal Society (1662) e Académie Royale des Sciences (1666), como instituições organizadoras do saber; e a criação da primeira revista científica precursora do modelo atual de comunicação científica, a Philosophical of Transaction (1665).

Segundo Kuramoto (2007, p. 147), é nessa época (século XVII) que surge o que virá a se constituir como a base do sistema de comunicação científica moderna: as revistas periódicas científicas. Em 1665, são criados, com alguns meses de 
intervalo, o Journal des Sçavans e o Philosophical of Transaction. O primeiro se dedicava às atividades de ciências e artes, propondo-se a difundir resumos analíticos de obras recentes, assim como elementos da atualidade científica. A revista inglesa se dispunha a publicar as comunicações originais apresentadas em sessões públicas. Essas publicações foram pioneiras e eram impressas periodicamente, consolidando as comunidades intelectuais e estabelecendo as primeiras redes de intercâmbio dos avanços científicos.

O surgimento da revista ou periódico científico, segundo Andrade e Oliveira (2005, p. 50), está associado às revoluções científicas ocorridas no século XVII. Ele se constituiu numa forma de comunicação que propiciou a troca de ideias e críticas das pesquisas desenvolvidas, tornando-as acessíveis a todos os estudiosos que debatiam sobre um determinado tema. Weitzel (2006, p. 84) relata que o periódico científico se tornou o principal marco da consolidação da estrutura da comunicação científica, pois surgiu dessa necessidade genuína dos pesquisadores de trocar experiências.

A comunicação científica desempenha papel central na ciência, de acordo com Mueller (2007, p. 128). Esse papel está relacionado ao fato de que, para ser considerado científico, um determinado conhecimento ou resultado de uma pesquisa deve ser aprovado pelos pares. A avaliação ocorre antes da publicação, durante o processo de "avaliação prévia", e depois da publicação, quando fica exposto à crítica de todos. Publicado e acessível a outros pesquisadores, poderá servir de ponto de partida para outras pesquisas, gerar novos conhecimentos e também ser contestado, possibilitando a criação de novos paradigmas. Essa é a natureza da verdade científica, sempre em evolução.

Greene (1998, p. 230) reitera e argumenta que as funções de uma revista em todo o mundo, geralmente, podem ser resumidas como memórias da ciência e como meio de divulgação de resultados de pesquisa, para a comunidade científica e para a sociedade. Além disso, a revista pode fornecer parâmetros para a avaliação da produção científica dos pesquisadores e das instituições. Comunidades científicas e grupos de pesquisa são ligados a institutos de pesquisa, sociedades científicas e universidades.

Kunsch (1992, p. 39) argumenta que a pesquisa é uma das finalidades básicas das universidades, ao lado do ensino e da extensão. Frequentemente, 
encontramos a expressão "produção científica" como forma de globalizar todas as atividades realizadas nesse setor. A autora descreve que há quase um consenso entre os estudiosos de que a universidade moderna, voltada para as atividades científicas, com ênfase na pesquisa e com plena liberdade de criação, teve início na Universidade de Berlim, em 1910, e destaca a expressão de Humboldt: "O que caracteriza as instituições de alta cultura é que elas consideram a ciência como um problema que não é nunca inteiramente resolvido".

Almeida Filho (2008, p. 168) descreve que, antes de 1810, quando foi fundada a Universidade de Berlim, os estudos, a pesquisa e mesmo a ciência eram realizados fora das instituições universitárias, que eram consideradas foco do conservadorismo, contra a revolução científica feita nas academias, nas bibliotecas, nos museus e nas sociedades científicas. Assim, a Universidade foi a última instância intelectual e ideológica que, com atraso, já no século XIX, incorpora um mandato que se tornou condição para a sua existência: a produção do conhecimento científico. No contexto atual, em que se debate os rumos da educação superior, no mundo, por Santos (2008, p. 14) e, no Brasil, por Almeida Filho (2008, p. 178), é relevante destacar a importância de estudos que abordem o papel da universidade tanto na pesquisa, quanto na formação de pessoal. No que diz respeito à percepção das universidades como espaço de produção e como difusão de conhecimentos, cabe ainda investigar, entre outros temas, a problemática da comunicação científica, ou seja, o surgimento e evolução das diversas formas de divulgação do conhecimento científico produzido no Brasil.

As universidades federais brasileiras, conforme menciona Mueller (2007, p. 137), são as principais produtoras de pesquisa do país, e a pesquisa depende de conhecimento já certificado e encontrado, sobretudo, nos periódicos. "Essa constatação nos remete à história da medicina brasileira e ao registro do início da comunicação científica, através da publicação de revistas científicas de medicina, desde o século XIX" (FERREIRA, 2004, p. 94).

Segundo Coimbra Jr. (2003, p. 1), a produção científica no Brasil cresce com velocidade, praticamente em todas as áreas do conhecimento. Na área de saúde, boa parte desse crescimento está associado à expansão e à consolidação da pósgraduação. Tomando como referência a biblioteca eletrônica SciELO, os indicadores também apontam para o predomínio das áreas da saúde e biomédicas; cerca da 
metade dos periódicos disponíveis na SciELO estão relacionados a essas áreas. Mas, apesar dos recursos tecnológicos e do aumento da produção científica, de acordo com Miranda e Pereira (1996, p. 380), o fator de impacto dos periódicos nacionais espelham a falta de tradição científica no país.

Buscando situar esse tema no "estado da arte", em termos de investigação sobre o desenvolvimento histórico da ciência no Brasil, foi realizada inicialmente uma revisão bibliográfica acerca do tema, a partir da seleção de artigos sobre comunicação científica, na fonte de informação: Scientific Eletronic Library Online SciELO.

A contribuição deste trabalho para a universidade insere-se no quesito de investigação e avaliação da comunicação científica na área da saúde, de como aconteceu o seu surgimento no Brasil, a apresentação dos primeiros periódicos científicos publicados no país e a discussão das tendências dessa produção. Esse estudo ganha maior importância pela identificação da "Gazeta Médica da Bahia", criada na Bahia, no século XIX, como o periódico mais antigo do Brasil, com circulação até a atualidade, completando, em 2012, 146 anos de existência, e pela motivação e interesse em investigar o seu surgimento e relevância no contexto da história da ciência.

O objetivo deste trabalho, portanto, é identificar como esse tema vem sendo abordado no campo científico, com vistas a verificar se estão sendo realizados estudos históricos que deem conta da criação de periódicos voltados à difusão dos resultados da pesquisa científica brasileira, verificando em que contexto esse tipo de publicação surgiu no Brasil e na Bahia, e quais foram os primeiros periódicos científicos publicados no Brasil, no século XIX. Essa revisão de literatura pretende, portanto, nortear a perspectiva a ser desenvolvida, numa futura pesquisa sobre o surgimento do periódico "Gazeta Médica da Bahia", no século XIX. Esse artigo, apresenta os resultados desse trabalho, expondo, inicialmente, a metodologia de revisão bibliográfica utilizada e, em seguida, os resultados da busca de publicações que tratam do tema na literatura indexada na SciELO. 


\section{0 método e a descrição da pesquisa}

Foi adotada a revisão exploratória de literatura, com a finalidade de reportar o conhecimento produzido em pesquisas prévias, destacando como o tema vem sendo abordado e os resultados apresentados à comunidade científica. Foram identificados os autores que pesquisam o tema, quais são as abordagens teóricometodológicas e os resultados apresentados, favorecendo a percepção de lacunas que possam existir no conhecimento existente. A revisão de literatura incluiu periódicos recuperados, após levantamento, na biblioteca virtual Scientific Eletronic Library Online - SciELO, constando dos seguintes passos:

a) seleção dos resumos a serem avaliados. Tomando como ponto de partida a identificação dos descritores: "comunicação científica", "comunicação científica no Brasil", "periódicos científicos brasileiros", "jornais médicos", "imprensa médica", "avaliação de artigos científicos" e "comunicação de ciência". A busca resultou em um total de 49 artigos com registro na base SciELO, de 1998 a 2012;

b) classificação dos resumos selecionados. Os 49 resumos dos trabalhos identificados foram lidos e classificados de acordo com as seguintes categorias de análise: ano de publicação, área de conhecimento, temática abordada; e

c) processamento e análise do conteúdo dos resumos. Elaboração de gráficos e tabelas contendo os resultados da classificação anterior como ponto de partida para a identificação de trabalhos que abordavam especificamente comunicação científica em saúde, no Brasil, até o século XIX, sendo destacados cinco artigos lidos na íntegra.

\section{Produção científica sobre comunicação científica no Brasil}

\subsection{Distribuição temporal dos resumos analisados}

Observa-se através do Gráfico 1, a tendência quanto ao número de artigos publicados e se nota que o período de 1998 a 2012 apresenta uma oscilação expressiva, iniciando com pouca produção, variando de um a dois artigos de 1998 a 2002, seguindo com razoável elevação até 2003 e declínio nos dois anos seguintes. A partir de 2005 é possível visualizar um aumento expressivo, que segue 
aumentando até 2007. A partir daí se inicia um processo considerável de redução, até 2008, seguido de queda total em 2009, ano em que não é registrada nenhuma produção. Em 2010, há uma pequena elevação, que segue crescente até 2011, e uma discreta redução em 2012.

Gráfico 1 - Evolução quantitativa da produção sobre CC no período de 1998/2012

\section{Número de artigos encontrados}

-Número de artigos encontrados

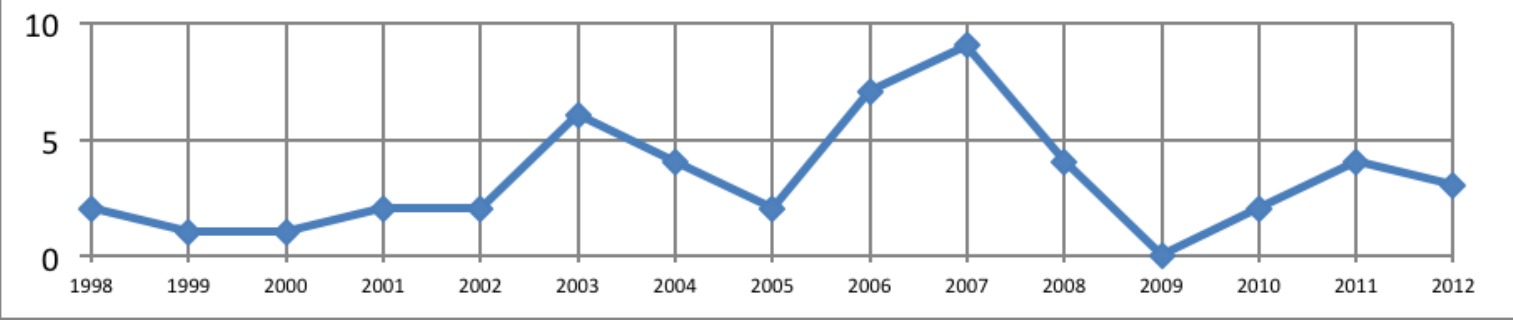

Fonte: Elaboração própria.

\subsection{Distribuição dos resumos por periódico, área e subáreas temáticas}

Os resumos foram classificados segundo sua inserção em determinadas áreas e subáreas temáticas, de acordo com as Tabelas de Áreas de Conhecimento da CAPES. Como se pode observar na Tabela 1, o maior número de trabalhos se localiza na área de Ciências Sociais Aplicadas, seguida de Ciências da Saúde, aparecendo também publicações nas áreas de Ciências Humanas e Ciências Agrárias.

Desagregando-se a classificação da área de Ciências Sociais Aplicadas, nas subáreas de Comunicação e Ciência da Informação, observa-se que o maior número de trabalhos se encontra na área de Ciência da Informação, representando $64 \%$ do total de trabalhos, sendo que a grande maioria destes foram publicados na revista Ciência da Informação.

A área de Ciências da Saúde abrange periódicos da subárea de Medicina e de Educação Física, com predominância da Medicina com 18\% de publicações. Na área de Ciências Humanas, os periódicos estavam nas subáreas de Antropologia, Sociologia e Psicologia, sendo em Psicologia o maior percentual, 8\%; e Ciências Agrárias com apenas um periódico na subárea de Agronomia. Os periódicos que 
mais aparecem na pesquisa são respectivamente: Ciência da Informação, Perspectivas em Ciência da Informação, História, Ciência, Saúde-Manguinhos e Psicologia USP.

Tabela 1 - Distribuição dos resumos por periódico, área de conhecimento e subárea temática

\begin{tabular}{|c|c|c|c|c|c|}
\hline $\begin{array}{l}\text { Área de } \\
\text { Conhecimento }\end{array}$ & $\begin{array}{l}\text { Subárea } \\
\text { temática }\end{array}$ & Periódicos & $\begin{array}{l}\mathbf{N}^{\circ} \text { de } \\
\text { resumos }\end{array}$ & $\%$ & $\begin{array}{l}\text { Total } \\
\%\end{array}$ \\
\hline \multirow{4}{*}{$\begin{array}{l}\text { Ciências } \\
\text { Sociais } \\
\text { Aplicadas }\end{array}$} & Comunicação & $\begin{array}{l}\text { Revista Brasileira de Ciências } \\
\text { da Comunicação }\end{array}$ & 1 & 2 & \multirow{4}{*}{65,3} \\
\hline & \multirow{3}{*}{$\begin{array}{ll}\text { Ciência } & \mathrm{da} \\
\text { Informação } & \end{array}$} & Ciência da Informação & 22 & 45 & \\
\hline & & $\begin{array}{l}\text { Perspectivas em Ciência da } \\
\text { Informação }\end{array}$ & 9 & \multirow[t]{2}{*}{19} & \\
\hline & & Subtotal & 32 & & \\
\hline \multirow{6}{*}{$\begin{array}{l}\text { Ciências da } \\
\text { Saúde }\end{array}$} & \multirow{4}{*}{ Medicina } & $\begin{array}{l}\text { História, Ciências, } \\
\text { Saúde - Manguinhos }\end{array}$ & 4 & 8 & \multirow{6}{*}{20,4} \\
\hline & & Acta Cirúrgica Brasileira & 2 & 4 & \\
\hline & & $\begin{array}{l}\text { Revista Brasileira de Cirurgia } \\
\text { Cardiovascular }\end{array}$ & 2 & 4 & \\
\hline & & Cadernos de Saúde Pública & 1 & 2 & \\
\hline & \multirow[t]{2}{*}{$\begin{array}{l}\text { Educação } \\
\text { Física }\end{array}$} & $\begin{array}{l}\text { Revista de educação Física e } \\
\text { Esporte }\end{array}$ & 1 & \multirow[t]{2}{*}{2} & \\
\hline & & Subtotal & 10 & & \\
\hline \multirow{5}{*}{$\begin{array}{l}\text { Ciências } \\
\text { Humanas }\end{array}$} & Antropologia & Horizontes Antropológicos & 1 & 2 & \multirow{5}{*}{12,3} \\
\hline & Sociologia & Sociologia & 1 & 2 & \\
\hline & \multirow{3}{*}{ Psicologia } & Psicologia Ciência e Profissão & 1 & 2 & \\
\hline & & Psicologia USP & 3 & \multirow[t]{2}{*}{6} & \\
\hline & & Subtotal & 6 & & \\
\hline $\begin{array}{l}\text { Ciências } \\
\text { Agrárias }\end{array}$ & Agronomia & Scientia Agrícola & 1 & 2 & 2,0 \\
\hline \multicolumn{3}{|l|}{ Total } & 49 & 100 & 100 \\
\hline
\end{tabular}

Fonte: Elaboração própria.

\subsection{Distribuição dos trabalhos por temática abordada}

Os 49 artigos analisados abordam seis temáticas principais (Tabela 2): Recursos Eletrônicos de Comunicação, com maior incidência, seguida de Avaliação de Periódicos Científicos, Editoração de Revistas Científicas, Periódicos CientíficosHistória, Autoria de Artigos Científicos e Ciência da Informação. Os artigos que não pertencentes a nenhum desses temas foram agrupados como "outros".

Os que tratam de Recursos Eletrônicos de Comunicação refletem como o uso das tecnologias de informação e comunicações afetaram positivamente a comunicação científica na difusão do conhecimento, e os impactos que vêm provocando nas pesquisas das universidades (SOUZA, 2003, p. 135). Na edição de artigos científicos (COSTA, 2006, p. 39), destacam como a informação científica em 
meio digital altera o comportamento de busca e uso da informação (CRESPO; CAREGNATO, 2006, p. 30), dão ênfase aos hipertextos e aos efeitos sociais dessas tecnologias (DIAS, 1999, p. 269), aos open-archives (GUANAES; GUIMARAES, 2012, p. 56) e também aos repositórios institucionais como ferramenta de gestão do conhecimento científico no meio acadêmico (LEITE; COSTA, 2006, p. 206), examinam a infraestrutura tecnológica para a utilização desses recursos de pesquisa no Brasil (PINHEIRO, 2003, p. 62).

Tabela 2 - Artigos por subárea temática

\begin{tabular}{|ll|l|l|}
\hline \multicolumn{2}{|l|}{ Artigos/Subárea temática } & $\begin{array}{l}\text { Número } \\
\text { resumos }\end{array}$ & de \\
\hline $1 . \quad$ Recursos eletrônicos de comunicação & 20 & 42 \\
\hline $2 . \quad$ Avaliação de Periódicos científicos & 7 & 14 \\
\hline $3 . \quad$ Editoração de revistas científicas & 6 & 12 \\
\hline 4. & Periódicos científicos-história & 6 & 12 \\
\hline 5. & Autoria de artigos científicos & 3 & 6 \\
\hline $6 . \quad$ Ciência da informação & 2 & 4 \\
\hline 7. & Outros & 5 & 10 \\
\hline Total & $\mathbf{4 9}$ & $\mathbf{1 0 0}$ \\
\hline
\end{tabular}

Fonte: Elaboração própria.

Alguns artigos discutem especificamente a publicação de periódicos eletrônicos em instituições de ensino e pesquisa, como o Instituto de Geociências da USP (OLIVEIRA, 2007, p. 59), o Centro de Informações Nucleares da Comissão Nacional de Energia Nuclear (NEVES, 2004, p. 116), a Universidade Federal de Santa Catarina (LOPES; SILVA, 2007, p. 21) e a Biblioteca Digital Brasileira do IBICT (TRISKA; CAFE, 2001, p. 92). Outros artigos se referem aos estudos com os periódicos Pesquisa Agropecuária Brasileira (BERTIN; FORTALEZA; SUHET, 2007, p. 83) e Informação \& Sociedade, como fontes primárias de informação (ARAUJO et al, 2006, p. 335) ou sobre a divulgação científica em Psicologia, através de um programa de rádio (NASCIMENTO et al, 2011, p. 880).

Os que examinam Avaliação de Periódicos Científicos analisam o Impacto da Avaliação da pós-graduação pela CAPES na qualificação e no aumento da produção acadêmica (LEAL; COIMBRA JR., 2008, p. 1), da metodologia desenvolvida para avaliação de conteúdo e desempenho de periódicos correntes brasileiros (KRZYZANOWSKI; FERREIRA, 1998, p. 16), de como a agricultura e a biodiversidade tem sido abordadas em ciências sociais, no Brasil, em artigos publicados nos últimos 20 anos (CARNEIRO; DANTON, 2012, p. 252); da pesquisa 
contemporânea em Educação Física, publicada em periódicos nacionais (ROSA; LETA, 2010, p. 121), da produção científicas de artigos em revistas brasileiras na área de ciências da informação (BUFREM, 2007, p. 38), dos resultados da cobertura midiática sobre política ambiental publicada no periódico O Estado de São Paulo, no ano de 2007 (MIGUEL, 2012, p. 111); e da análise da produção científica da ANPED e da Intercom em comunicação educativa para verificar os autores nacionais e internacionais mais citados na área (MOUSTAFA; MAXIMO, 2003, p. 96-101).

Os que abordam Editoração de revistas científicas apresentam: editoração de revistas brasileiras através do Sistema Eletrônico de Editoração de Revistas - SEER (FREIRE et al, 2007, p. 83), análise de critérios de editoração, difusão e indexação de produção científica na área de Geociências (OLIVEIRA, 2005, p. 34); avaliação de artigos científicos para editoração na área biomédica (GREENE, 1998, p. 23232), terminologia e atribuições adotadas pelos editores das revistas brasileiras na área de cirurgia (POBLACION, 2003, p. 497), instruções dos editores das revistas brasileiras de cirurgia, baseadas nos requisitos de Vancouver (PELLIZZON et al, 2007, p. 503) e aspectos técnicos e éticos do trabalho de editoração de artigos por produção quantificável, sem compromisso social de disseminar conhecimento (GUEDES, 2011, p. 387).

Os trabalhos incluídos na categoria Periódicos Científicos-História descrevem o surgimento dos primeiros periódicos científicos publicados no Brasil (FREITAS, 2006, p. 35), a história institucional do jornalismo médico brasileiro entre 1827 e 1843 (FERREIRA, 2004, p. 93), a divulgação científica sobre o cólera no "GrãoPará”, no século XIX (BELTRÃO, 2002, p. 239), a pesquisa documental sobre a história da hanseníase no Brasil (SANTOS, 2003, p. 415) e a contribuição de Juliano Moreira na Gazeta Médica da Bahia (JACOBINA; GELMAN, 2008, p. 1077).

Os que discutem a autoria de artigos científicos analisam critérios de autoria em trabalhos científicos, visando à credibilidade da ciência (MONTEIRO et al, 2004, p. 3); à questão da fraude na prática da autoria (GARCIA et al, 2010, p. 559), e à coautoria como indicador de redes de colaboração científica no Programa de Pósgraduação em Epidemiologia da UFPel (MAIA; CAREGNATO, 2008, p. 18).

Os que tratam de Ciência da Informação mostram fundamentos históricos e teóricos no campo científico da informação (FREIRE, 2006, p. 6) e avaliação do 
artigo de Wersing e Neveling, que propõe um fundamento social para a ciência da informação (FREIRE, 2003, p. 50).

Os outros artigos, que não puderam ser distribuídos nas subáreas temáticas apresentadas, analisam temas variados, a saber: os programas de pesquisa BIOTA/FAPESP sobre biodiversidade (SCARANO, 2007, p. 439), a atuação profissional de bibliotecários nos processos de comunicação científica em periódicos de Psicologia (SERRADAS, 2011, p. 437), a construção de um modelo conceitual de gestão do conhecimento científico no contexto acadêmico (LEITE; COSTA, 2007, p. 92), a modelagem de um indicador bibliométrico para análise de dispersão geográfica e para análise de conhecimento (RUNMLER, 2006, p. 63) e a citação e a difusão do artigo científico e as relações nos meios sociais pertinentes ao autor da citação (JARDIM, 2011, p. 357).

\section{Características dos estudos históricos sobre "cc" no Brasil}

Uma vez traçado o panorama da produção sobre comunicação científica, foram selecionados os trabalhos que contemplam uma abordagem histórica, buscando identificar como vem sendo estudado o surgimento e o desenvolvimento da comunicação científica no Brasil. Para isso, foram utilizados, não somente os artigos selecionados na SciELO, mas também alguns textos publicados sob o formato de livros ou capítulos de livros.

Com base nessa revisão, é possível afirmar que o periodismo, ou imprensa em geral, surge no Brasil no século XIX, quando são afrouxadas as amarras da política colonial portuguesa, e com a transformação brasileira de colônia à sede da Corte, em 1808. Freitas (2006, p. 55) discorre que, embora as condições artificialmente criadas tivessem o intuito de transplantar as instituições portuguesas para o Brasil, servindo às necessidades da corte portuguesa, contribuíram para iniciar a institucionalização da cultura brasileira e estimularam os brasileiros a elaborar uma identidade nacional e a se organizarem como nação.

A origem do jornal médico brasileiro, segundo Ferreira (2004, p. 95), confunde-se com a da tardia instituição da imprensa no Brasil, que data da primeira década do século XIX, quando termina a proibição que, durante todo o período colonial, colocou sob suspensão a impressão tipográfica. Esse fato redimensiona a 
importância do jornalismo médico, à medida que ele pode ser abordado como parte das transformações culturais produzidas pela liberdade de imprensa.

A imprensa régia, segundo estudos de Rizzini (1977, p. 170), foi fundada em 1808. O governo português mandou buscar na Inglaterra uma impressão, que importou para o Brasil por 100 libras esterlinas, pois necessitava divulgar seus atos e seus decretos. Com a criação da Imprensa Régia, não se suspendeu de imediato a prática da censura e o controle governamental sobre a imprensa. Qualquer texto a publicar ainda deveria ter autorização do governo para ser impresso e publicado, observa Ferreira (2004, p. 95).

Freitas (2006, p. 56) observa que o primeiro periódico impresso no Brasil, a Gazeta do Rio de Janeiro, em 1808, realizou o papel de divulgador dos "assuntos científicos", noticiando a produção de obras, a realização de cursos e a produção e venda de livros e textos científicos. Também em 1808, a Imprensa Régia imprime as "Reflexões sobre alguns dos meios propostos por mais conducentes para melhorar o clima da cidade do Rio de Janeiro", do médico da Real Câmara Manoel Vieira da Silva. Este é o primeiro trabalho médico de Saúde Pública impresso no Brasil.

Depois surgem outras publicações (Tabela 3), quais sejam: a Idade d'Ouro do Brasil, a Gazeta da Bahia, as Variedades ou Ensaios de Literatura; O Patriota, Jornal Literário, Político, Mercantil \& C. do Rio de Janeiro; os Annaes Flumineneses de Sciencias, Artes e Literatura; o Jornal Scientifico, Economico e Literario; o Propagador das Sciencias Medicas, único periódico desse período de cunho científico; e O Beija-Flor - Annaes Brasileiro de Sciencia Politica, Litteratura, conforme descreve Ferreira (2004, p. 55).

O que hoje chamamos periódico científico, era naquela época denominado como revista literária, jornal de cultura, jornal de ciências e artes e jornal literário. Essa denominação estava de acordo com o conhecimento e cultura científica da época, mais "miscelânica" do que especializada, observa Freitas (2006, p. 57). Os jornais literários traziam artigos técnicos científicos redigidos com a linguagem própria da ciência e com várias observações sobre experimentos realizados, gráficos, tabelas e fórmulas. Traziam também artigos de periódicos estrangeiros, comentários de outras obras e resumos de textos. Freitas (2006, p. 64) considera que os jornais literários, publicados no início do século XIX, podem ser reconhecidos 
como os primeiros periódicos científicos brasileiros, tendo sido importantes formadores da cultura científica da época.

Tabela 3 - Jornais de sciencias, artes e litteratura

\begin{tabular}{|c|c|c|c|}
\hline Periódico & $\begin{array}{l}\text { Ano de } \\
\text { publicação }\end{array}$ & Local & Temática \\
\hline Gazeta do Rio de Janeiro & 1808 & Rio de Janeiro & $\begin{array}{l}\text { Assuntos científicos, produção de obras, } \\
\text { realização de cursos, produção e venda } \\
\text { de livros e textos científicos. }\end{array}$ \\
\hline Idade d'Ouro do Brasil & & Bahia & \\
\hline Gazeta da Bahia & & Bahia & \\
\hline $\begin{array}{l}\text { As Variedades ou } \\
\text { Ensaios de Literatura }\end{array}$ & 1812 & Bahia & $\begin{array}{l}\text { Discursos, extratos de história antiga e } \\
\text { moderna, viagens, trechos de autores } \\
\text { clássicos, anedotas. }\end{array}$ \\
\hline $\begin{array}{l}\text { O Patriota, Jornal } \\
\text { Litterario, Politico, } \\
\text { Mercantil e Cientifico do } \\
\text { Rio de Janeiro }\end{array}$ & 1813-1814 & Rio de Janeiro & $\begin{array}{l}\text { Técnicas de navegação, mineralogia, } \\
\text { botânica, medicina, literatura, história e } \\
\text { geografia. }\end{array}$ \\
\hline $\begin{array}{ll}\text { Annaes } & \text { Fluminenses de } \\
\text { Sciencias, } & \text { Artes e } \\
\text { Literatura, } & \text { Publicados } \\
\text { por huma } & \text { Sociedade } \\
\text { Philo-Tecnica no Rio de } \\
\text { Janeiro }\end{array}$ & 1822 & Rio de Janeiro & 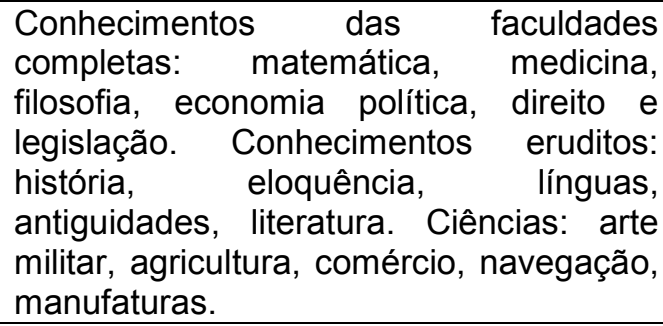 \\
\hline $\begin{array}{l}\text { O Jornal Scientifico, } \\
\text { Econômico e Literário }\end{array}$ & 1826 & Rio de Janeiro & $\begin{array}{l}\text { Ciências, artes, poesias, belas letras, } \\
\text { viagens e variedades. }\end{array}$ \\
\hline $\begin{array}{l}\text { O Propagador das } \\
\text { Sciencias Medicas ou } \\
\text { Annaes de Medicina, } \\
\text { Cirurgia e Pharmacia } \\
\text { Para o Império do Brasil } \\
\text { e Nações Estrangeiras }\end{array}$ & 1827 & Rio de Janeiro & Medicina, cirurgia, farmácia. \\
\hline $\begin{array}{l}\text { Revue Bresiliene, ou } \\
\text { Recuel de Morceuax } \\
\text { originaux sur lês affaires } \\
\text { Intérieures de L'empire, } \\
\text { la politique, et sur La } \\
\text { statistique }\end{array}$ & 1830 & Rio de janeiro & $\begin{array}{l}\text { Notícias de outros países e reflexões } \\
\text { políticas }\end{array}$ \\
\hline $\begin{array}{l}\text { O Beija-Flor: Annaes } \\
\text { Brasileiros de Sciencia, } \\
\text { Política e Literatura }\end{array}$ & $1830-1831$ & Rio de Janeiro & $\begin{array}{l}\text { Textos noticiosos, políticos, literários e de } \\
\text { interesses geral. }\end{array}$ \\
\hline
\end{tabular}

Fonte: Elaboração própria.

Os primeiros jornais médicos brasileiros seguiram à risca o modelo da Europa. Ferreira (2004, p. 94) constatou que na Europa, no final do século XVIII, assim como no Brasil, no século XIX, o jornal médico periódico assumiu um papel estratégico, no esforço de institucionalização e de afirmação da Medicina. Funcionando como arena de legitimação social e de disputas científicas e 
profissionais, jornais e revistas médicas se dedicavam à compilação de textos originais, à reprodução da correspondência trocada entre médicos e cientistas e à divulgação das atividades desenvolvidas sob o auspício de alguma sociedade ou academia de medicina.

Freitas (2006, p. 64) confirma a descrição de Ferreira (2004, p. 94), argumentando que a realidade sociopolítica brasileira não se mostrava propícia à publicação de periódicos especializados, e, para que novos periódicos se firmassem, foi necessário que estivessem apoiados em agremiações científicas, as quais fundaram um novo jornalismo científico. Algumas delas foram a Sociedade de Medicina do Rio de Janeiro (1831) e a Academia Imperial de Medicina do Rio de Janeiro (1835), que, segundo Freitas (2006, p. 64) publicaram inúmeros periódicos, iniciando com o Semanário de Saúde Pública (1831-1833). Outros foram se sucedendo, como a Revista Médica Fluminense (1835-1841), a Revista Médica Brazileira (1841-1845), Os Annaes de Medicina Brasiliense - Jornal da Academia Imperial de Medicina do Rio de Janeiro (1845-1849), Annaes Brasilienses de Medicina - Jornal d'Academia Imperial de Medicina do Rio de Janeiro (1849-1885) e os Annaes da Academia de Medicina do Rio de Janeiro (1885-1902) (Tabela 4).

Segundo Ferreira (2004, p. 94), a história do jornalismo médico tem sido imensamente ignorada na Europa e, ao analisar os primeiros jornais médicos brasileiros, investigou a maneira como esse jornalismo interveio no ambiente institucional e intelectual da medicina no Brasil. Ele constatou que sua trajetória inicial se caracterizou pela simbiose entre negócios (interesses comerciais das editoras instaladas na corte), política (conflitos relacionados a disputas pela hegemonia política no contexto de consolidação do estado imperial) e ciência (movimento de institucionalização e afirmação científica da medicina).

Ferreira (2004, p. 94) apresenta como primeiros jornais médicos brasileiros: Propagador de Ciências Médicas (1827-1828), Semanário de Saúde Pública (18311833), Diário de Saúde (1835-1836), Revista Médica Fluminense (1835-1841); e Revista Médica Brasileira (1841-1843). E argumenta que, mesmo ligados às sociedades médicas da Corte, os primeiros jornais médicos nacionais encontraram sérias dificuldades para sobreviver. Faltavam-lhes colaboradores assíduos e assinantes profissionalmente vinculados à medicina. Precisavam jurar que seus propósitos eram puramente científicos, como única forma de se prevenir do risco de 
serem identificados como porta vozes de alguma facção política, principalmente daqueles que faziam oposição ao governo imperial.

Tabela 4 - Primeiros periódicos de saúde publicados no Brasil

\begin{tabular}{|c|c|c|c|}
\hline Título & $\begin{array}{l}\text { Ano(s) de } \\
\text { publicação }\end{array}$ & Local & $\begin{array}{l}\text { Citado pelo(s) } \\
\text { pesquisador(es) }\end{array}$ \\
\hline $\begin{array}{l}\text { Propagador das Sciencias Medicas ou Annaes } \\
\text { de Medicina, Cirurgia e Pharmacia para o } \\
\text { Império do Brasil e Nações Extrangeiras }\end{array}$ & $1827-1828$ & Rio de Janeiro & $\begin{array}{l}\text { Ferreira (2004) e } \\
\text { Freitas (2006) }\end{array}$ \\
\hline Semanário de Saúde Publica & $1830-1833$ & Rio de Janeiro & $\begin{array}{l}\text { Ferreira (2004) e } \\
\text { Freitas (2006) }\end{array}$ \\
\hline Diário de Saúde & $\begin{array}{l}1835- \\
21836\end{array}$ & Rio de Janeiro & Ferreira (2004) \\
\hline Revista Medica Fluminense & $1835-1841$ & Rio de Janeiro & $\begin{array}{l}\text { Santos (2003), } \\
\text { Ferreira (2004) e } \\
\text { Freitas (2006) }\end{array}$ \\
\hline Revista Medica Brasileira & $1841-1843$ & Rio de Janeiro & $\begin{array}{l}\text { Ferreira (2004) e } \\
\text { Freitas (2006) }\end{array}$ \\
\hline Archivo Medico Brasileiro & $1845-1848$ & Rio de Janeiro & Santos (2003) \\
\hline $\begin{array}{l}\text { Annaes de Medicina Brasiliense: Jornal da } \\
\text { Academia Imperial de Medicina do Rio de } \\
\text { Janeiro }\end{array}$ & $1845-1849$ & Rio de Janeiro & Freitas (2006) \\
\hline $\begin{array}{l}\text { Annaes Brasileiros de Medicina: Jornal } \\
\text { d'Academia Imperial de Medicina do Rio de } \\
\text { Janeiro }\end{array}$ & $1849-1885$ & Rio de Janeiro & Freitas (2006) \\
\hline Gazeta do Hospitais do Rio de Janeiro & 1852- & Rio de Janeiro & Santos (2003) \\
\hline Gazeta Medica da Bahia & $1866-2012$ & Bahia & $\begin{array}{l}\text { Jacobina; Gelman } \\
(2008)\end{array}$ \\
\hline Gazeta Medica Brasileira & 1882 & Rio de Janeiro & Santos (2003) \\
\hline $\begin{array}{l}\text { Annaes da Academia de Medicina do Rio de } \\
\text { Janeiro }\end{array}$ & $1885-1902$ & Rio de Janeiro & Freitas (2006) \\
\hline Revista Brazileira de Oftalmologia & 1888- & Rio de Janeiro & Santos (2003) \\
\hline
\end{tabular}

Fonte: Elaboração própria.

O Propagador das Ciências Médicas, segundo descrição de Ferreira (2004, p. 96) foi lançado na Corte, em janeiro de 1827, pelo editor francês, Pierre François Plancher, com a colaboração do médico Joseph François Xavier Sigaud, também 
francês. Este percebeu as carências da classe médica do Rio de Janeiro, e coubeIhe o desafio de estabelecer novos padrões de produção e circulação de conhecimento entre os praticantes da medicina. Para incentivar médicos e cirurgiões, comprometeu-se a publicar, sem alterar o texto original, a fim de evitar que o jornal se envolvesse com o acirrado debate teórico das diferentes doutrinas médicas. Mesmo assim, não foi bem sucedido, pois eles não estavam preparados para publicar e debater suas ideias. O jornal passa a editar apenas traduções feitas por Sigaud, e, em janeiro de 1828, é extinto.

Com a fundação da Sociedade de Medicina do Rio de Janeiro, Ferreira (2004, p. 98) descreve que Sigaud foi encarregado de criar um novo jornal médico, e, em outubro de 1830, ele apresentou a seus pares o projeto que deu origem ao Semanário de Saúde Pública. O jornal divulgava as atividades da entidade, promovia a circulação do conhecimento, privilegiando assuntos relacionados à saúde pública, cujo ponto alto foram os relatórios da comissão de salubridade sobre as epidemias de febre intermitente, no Rio de Janeiro, e temas como a crítica dos hospitais, a venda de remédios secretos e os maus-tratos dispensados aos escravos. Para o financiamento, contou com a ajuda dos sócios titulares e de Plancher, que o imprimia em sua famosa Tipografia Imperial. Mas, o jornal só circulou até junho de 1833. O encerramento da revista anunciava a extinção da Sociedade Médica do Rio de Janeiro; suas recomendações relativas à melhoria da saúde pública, sobretudo, as de combate às epidemias, eram desprezadas pelo governo.

Ainda segundo Ferreira (2004, p. 100), para evitar a extinção definitiva do Jornal Médico no Brasil, Sigaud tentou negociar junto ao governo Imperial a possibilidade de colaborar com a edição de um novo periódico mensal, a Revista Médica Fluminense. Nessa conjuntura é criada a Academia Imperial de Medicina, que assume o periódico como o seu jornal médico oficial. Enquanto o Semanário de Saúde Pública deu ênfase aos problemas relacionados à saúde pública, a Revista Médica Fluminense assumiu uma feição corporativa, dando maior atenção aos interesses profissionais e institucionais dos acadêmicos. Era editada por Meirelles, o próprio presidente da Academia Imperial de Medicina, que impôs se limitar às ciências, com imparcialidade absoluta e estranho a todas as divisões de opinião. 
Mas, os privilégios corporativos, concedidos aos membros da academia, tinham como contrapartida a obediência e total lealdade aos interesses da elite imperial.

Ao mesmo tempo em que saiu o primeiro número dessa revista, em 1835, sai o Diário de Saúde ou Efemerídes das Ciências Médicas e Naturais do Brasil, dirigido por Sigaud e impresso pela Tipografia Imperial, de Plancher. Com isso, argumenta Ferreira (2004, p. 101), estabelece-se a concorrência no campo do jornalismo médico. A decisão de Sigaud de criar o seu próprio jornal médico se deu às lutas internas da Sociedade Médica do Rio de Janeiro. Ele critica severamente a passividade de seus colegas por terem aceitado a extinção da Sociedade, para transformá-la em uma instituição oficial, a Associação Imperial de Medicina. Livre dos constrangimentos políticos sofridos por essa sociedade científica, o Diário de Saúde anunciava sem medo que seu único objetivo era a conservação da saúde pública, e convocou para isso, todos os médicos, cirurgiões, farmacêuticos e naturalistas interessados no assunto. A maioria dos trabalhos nacionais publicados eram sobre higiene, já os trabalhos estrangeiros eram sobre terapêutica.

O Diário de Saúde foi extinto em 1836, ficando a Revista Médica Fluminense como única publicação do gênero em circulação no Brasil. Com a mudança do editor para Silva Maia, de perfil eminentemente acadêmico, não consegue dar estabilidade ao periódico. Sob constante ameaça de extinção da revista, via-se obrigado a reprisar as mesmas críticas feitas por Meirelles de falta de recursos do governo e de indiferença dos médicos e cirurgiões da Corte. A maior parte dos assinantes da Revista Médica Fluminense provinha da parte intelectualizada da população, e não da medicina. Para a solução dos problemas enfrentados, elege-se outro editor para a revista, o médico José Rego, maior higienista da segunda metade do século XIX. A quantidade de assinantes chegou, em 1839, a 210. A publicação foi suspensa em março de 1841 e reaparece em maio do mesmo ano com outro nome, Revista Médica Brasileira. Finalmente o jornal consegue abrangência geográfica da população e subsídio oficial, e a mudança de nome foi uma homenagem a isso. $O$ governo autoriza que parte da verba destinada à Associação fosse destinada à impressão do periódico, mas, mesmo assim, não cobria as despesas. O fim inesperado da Revista Médica Brasileira, ocorrido em março de 1843, encerrou o ciclo de publicações de jornais médicos. Em junho de 1845, o jornal médico semanal ou mensal aberto à colaboração externa foi substituído por um novo tipo de 
publicação, os Anais de Medicina Brasiliense, que vinham ao público com muita regularidade, uma vez por ano, resumindo as atividades acadêmicas, e publicando somente os trabalhos apresentados pelos sócios. Os Anais não tinham, portanto, o mesmo caráter dos jornais (FERREIRA, 2004, p. 105).

No decorrer desta pesquisa, foram encontrados mais alguns periódicos publicados no século XIX, através de um trabalho ainda em andamento do pesquisador Vicente Saul Moreira dos Santos, para o International Leprosy Association Global Project on The History of Leprosy, sediado na Universidade de Oxford, Inglaterra. O estudioso pesquisou sobre fontes relativas à lepra, em bibliotecas e arquivos localizados no Rio de Janeiro. De acordo com Santos (2003), as fontes primárias utilizadas em sua pesquisa foram: Revista Médica Fluminense (1835-1841), Archivo Médico Brasileiro (1845-1848), Gazeta dos Hospitais do Rio de Janeiro (1852-), Gazeta Médica Brasileira (1882) e Revista Brasileira de Ophtalmologia (1888-).

A Gazeta Médica da Bahia, periódico científico mais antigo do país, ainda em circulação até 2012, foi editado pela primeira vez em 1866. Um ano antes, um grupo de médicos resolveu formar uma associação na Bahia para praticar "assuntos" científicos. Eles assumiram um compromisso de se reunir duas vezes por mês, à noite, relatam Jacobina e Gelman (2008, p. 1078). Jonhn Paterson, que era escocês, e autor da criação dessa sociedade médica, junto aos portugueses José Francisco da Silva Lima e Otto Eduard Henry Wucherer, que formavam a tríade mais famosa da medicina tropical da Bahia, reuniam-se com mais três sócios, professores da Faculdade de Medicina da Bahia: Antônio José Alves (cirurgia), Antônio Januário de Farias (clínica médica) e o médico Manoel Maria Pires Caldas (cirurgia). Foi no seio dessa sociedade, a qual aderiram outros médicos, inclusive estrangeiros, que nasceu o pensamento "progressista" de criar na Bahia um periódico médico, sendo autor da proposta o professor Januário de Farias.

Os sócios se cotizaram para fazer face às despesas e, em 10 de julho de 1866, publicaram o primeiro número da Gazeta Médica da Bahia. A revista foi suspensa por um ano, em 1870, e por dois anos, em 1874, aparentando, segundo Jacobina e Gelman (2008, p. 1081) que, como tantas outras revistas, iria se extinguir. Mas, isso não ocorre, e essa revista de qualidade, publicada de modo quase ininterrupto, na segunda metade do século XIX e nas primeiras décadas do 
século $\mathrm{XX}$, período de seu maior prestígio, permaneceu, apesar de haver uma lacuna posterior em sua trajetória. Jacobina e Gelman (2008, p. 1081) descrevem que na ocasião da publicação do número jubilar da Gazeta, Juliano Moreira (1818) enfatiza que ela se impôs desde o seu início, chamando a atenção das publicações do "Velho Mundo" de tal modo, que, no seu primeiro ano de vida, recebeu o apoio do British Medical Journal, importante semanário médico da Associação Médica da GrãBretanha.

Também foram encontrados registros das recomendações dos médicos sobre tratamentos a serem observados pelos enfermos, que circularam através da imprensa e que muito auxiliaram no combate à epidemia do cólera, no Grão-Pará, no século XIX. Através do trabalho de Beltrão (2002, p. 239), foi constatado o quanto essas instruções, veiculadas pelos médicos em jornais de grande circulação, revelaram a capacidade pedagógica e persuasiva dos profissionais de saúde, através desse tipo de comunicação. O Treze de Maio (1855), relata Beltrão (2002, p. 242), publicava artigos com instruções do Santé Universelle (periódico francês) sobre a moléstia e os medicamentos para cada sintoma, e um diário denominado Duas Palavras, sobre a epidemia reinante, em que constavam guias elaborados pelos médicos para informar ao público sobre a doença. O Publicador Paraense, divulgou em 1853 sobre a existência do cólera-morbus em alguns países da Europa, e o governo Imperial se preparou para resguardar a província de Pernambuco, cujo porto tocava primeiramente a embarcação proveniente da Inglaterra. E ainda, o Diário do Gram-Pará (1855), que, segundo Beltrão (2002) enfatiza a coleção do período estudado (século XIX), não foi localizado no Brasil, e sim no Arquivo Histórico Diplomático do Ministério dos Negócios Estrangeiros de Portugal. Segundo Beltrão (2002, p. 241), no Rio de Janeiro, essas divulgações eram feitas através do Jornal do Comércio e do Diário do Rio de Janeiro (Tabela 5).

Tabela 5 - Primeiros jornais diários de grande circulação que veiculavam notícias da área médica

\begin{tabular}{|l|l|l|}
\hline Título & Local & Ano \\
\hline Publicador Paraense & Grão-Pará & 1853 \\
\hline Diário do Gram-Pará & Grão-Pará & 1855 \\
\hline Diário do Rio de Janeiro & Rio de Janeiro & 1855 \\
\hline Jornal do Comércio & Rio de Janeiro & 1855 \\
\hline Treze de Maio & Grão-Pará & 1855 \\
\hline
\end{tabular}

Fonte: Elaboração própria. 
Em síntese, podemos constatar que os periódicos surgidos no século $\mathrm{XIX}$, apesar de apresentarem enfoques diversos, podem ser agrupados nas seguintes categorias:

a) periódicos publicados no Brasil do século XIX até 1830 - jornais de ciência, artes (técnicas) e literatura, que publicavam, de acordo com o próprio conhecimento e cultura da época, textos literários, variedades, miscelâneas, trabalhos técnicos e traduções de artigos estrangeiros. Não publicavam conteúdo especializado;

b) jornais e revistas médicos - publicações científicas que editavam artigos científicos, relatos de pesquisas e de experiências práticas, traduções de artigos científicos estrangeiros e notícias da medicina na Europa e traduções de revistas, principalmente de periódicos médicos franceses, uma prática que permanece até o final do século XIX; e

c) jornais de grande circulação que veiculavam notícias da área médica. Percebe-se a preocupação de divulgação de epidemias e doenças em jornais de grande circulação, através de alertas e cartas, como uma medida de saúde pública.

\section{Considerações finais}

A comunicação científica é um tema eminentemente interdisciplinar e de grande importância para o desenvolvimento da ciência, pois está intimamente ligada ao desenvolvimento da pesquisa na universidade. O periódico científico é o meio mais utilizado para disseminar os resultados das pesquisas na área da saúde, e cumpre funções que outorgam prestígio e reconhecimento aos pesquisadores no meio científico.

Como vimos, existem poucas publicações de cunho histórico sobre o surgimento da comunicação científica no Brasil, e, portanto, ainda é muito pouco o que se sabe a respeito da pesquisa científica brasileira. Até que ponto podemos considerar como comunicações científicas o que foi editado no Brasil, principalmente no início do século XIX? Há que se considerar que o fazer científico no Brasil, nesse período, muitas vezes, era literalmente copiado da Europa, principalmente da França, o que não é de se estranhar, já que Portugal seguia o Modelo Educacional 
Bonapartista e o Brasil permaneceu com essa herança. De qualquer modo, é nesse período que se inicia a construção da comunicação científica no país.

A revisão dos artigos que abordam esse tema demonstra que, no século XIX, a comunicação sistematizada da ciência somente ocorria de forma mais estável se estava atrelada a instituições da mesma finalidade. A maioria dos periódicos publicados nesse período, mesmo vinculados a instituições como Academias ou Sociedades, durou meses ou poucos anos, e isso era um reflexo da falta de interesse de médicos e cirurgiões, dos escassos recursos destinados à pesquisa científica, principalmente pelo descaso do governo. Outra característica era o imediato aparecimento de outra revista, que substituía a anterior, e isso se processou repetidamente. A interseção entre medicina e política era um traço marcante da elite médica brasileira, e, na maioria das vezes, prevaleciam valores, clientelismo e força do prestígio.

A Gazeta Médica da Bahia merece destaque por ter sido criada em 1866 e ainda permanecer até 2012. De acordo com Teixeira (2002, p. 13), na década de sessenta, do século XIX, não havia no Brasil pesquisa sistematizada em Medicina. Havia um desafio a enfrentar: "a percepção de patologias exuberantes, resultantes de múltiplas origens", e, desse desafio, iniciou-se a história da Gazeta Médica da Bahia, que gerou a Escola Tropicalista Baiana, verdadeiramente o "primeiro núcleo de pesquisa médica", que se constituiu no Brasil naquela época. Apesar de sua importância histórica, a mesma é citada em apenas um artigo, dos recuperados na SciELO no período estudado. A constatação dessa lacuna nos anima a propor uma investigação mais aprofundada sobre o surgimento e sobre as características da Gazeta Médica da Bahia em seus primeiros anos de publicação. Afinal, entender as origens da comunicação científica desde os seus primórdios e observar sua evolução até a utilização de meios eletrônicos, discutir as facilidades geradas pela revolução nos meios de comunicação na contemporaneidade e o possível impacto das tecnologias emergentes, são questões que merecem ainda ampla discussão. 


\section{Referências}

ALMEIDA FILHO, N. Universidade nova no Brasil. In: SANTOS, B. S; ALMEIDA FILHO, N. A universidade no século XXI: para uma universidade nova. Coimbra: Angellara, 2008. p. 107-257.

ANDRADE, M. E. A; OLIVEIRA, M. A ciência da informação no Brasil. In: OLIVEIRA, $M$. et al. Ciência da informação e biblioteconomia: novos conteúdos e espaços de atuação. Belo Horizonte: Editora UFMG, 2005. p. 45-60.

ARAUJO, E. A. et al. Periódico eletrônico Informação \& Sociedade: estudos impactos no contexto da comunicação científica. Perspectivas em Ciência da Informação, Belo Horizonte, v. 11, n. 3, p. 335-347. 2006.

BELTRÃO, J. F. Autoridade médica e divulgação científica no Grão-Pará flagelado pelo cólera: século XIX. Horizontes Antropológicos, Porto Alegre, v. 8, n. 17, p. 239-252, 2002.

BERTIN, P. R. B.; FORTALEZA, J. M.; SUHET, A. R. Paradigma atual da comunicação científica e introdução da revista Pesquisa Agropecuária Brasileira (PAB) no canal eletrônico. Perspectivas em Ciência da Informação, Belo Horizonte, v. 12, n. 3, p. 21-40, 2007.

BUFREM, L. S. et al. Produção científica em ciência da informação: análise temática de artigos de revistas brasileiras. Perspectivas em Ciência da Informação, Belo Horizonte, v. 12, n. 1, p. 38-49. 2007.

CARNEIRO, M. J.; DANTON, T. Agricultura e biodiversidade nas ciências sociais brasileiras: alimentando a comunicação entre ciências e políticas públicas.

Sociologias, Porto Alegre, v. 14, n. 30, p. 252-289, 2012.

COIMBRA JR., C. E. A. Desafios da produção e da comunicação científica em saúde no Brasil. Cadernos de Saúde Pública, Rio de Janeiro, v. 19, n. 1, p. 1-4, 2003.

CÔRTES, P. L. Considerações sobre a evolução da ciência e da comunicação científica. In: POBLACION, D. A.; WITTER, G. P.; SILVA, J. F. M. (Orgs.).

Comunicação e produção científica: contexto, indicadores e avaliação. São Paulo: Angellara, 2006. p. 35-79.

COSTA, S. M. S. Filosofia aberta, modelos de negócios e agências de fomento: elementos essenciais a uma discussão sobre o acesso aberto à informação científica. Ciência da Informação, Brasília, v. 35, n. 2, p. 39-50, 2006.

CRESPO, I. M.; CAREGNATO, S. E. Padrões de comportamento de busca e uso da informação por pesquisadores de biologia molecular e biotecnologia. Ciência da Informação, Brasília, v. 35, n. 3, p. 30-38. 2006.

DIAS, C. A. Hipertexto: evolução histórica e efeitos sociais. Ciência da Informação, Brasília, v. 28, n. 3, p. 269-277, 1999. 
FERREIRA, L. O. Negócio, política, ciência e vice-versa: uma história institucional do jornalismo médico brasileiro entre 1827 e 1843. História, Ciência, Saúde Manguinhos, Rio de Janeiro, v. 11, supl. 1, p. 93-107. 2004.

FREIRE, G. H. Ciência da informação: temática, história e fundamentos.

Perspectivas em Ciência da Informação, Belo Horizonte, v. 11, n. 1, p. 6-19. 2006.

FREIRE, G. H. et al. Uso do SEER para formatação de serviço de resumos: revista Pesquisa Brasileira em Ciência da Informação e Biblioteconomia. Ciência da Informação, Brasília, v. 36, n. 3, p. 83-88, 2007.

FREIRE, I. M. O olhar da consciência possível sobre o campo científico. Ciência da Informação, Brasília, v. 32, n. 1, p. 50-59, 2003.

FREITAS, M. H. Considerações acerca dos primeiros periódicos científicos brasileiros. Ciência da Informação, Brasília, v. 35, n. 3, p. 54-66, 2006.

GARCIA, C. C. et al. Autoria em artigos científicos: os novos desafios. Revista Brasileira de Cirurgia Cardiovascular, São Paulo, v. 25, n. 4, p. 559-567, 2010.

GRENNE, L. J. O dilema do editor de uma revista biomédica: aceitar ou não aceitar. Ciência da Informação, Brasília, v. 27, n. 2, p. 230-232, 1998.

GUANAES, P. C. V.; GUIMARAES, M. C. S. Modelos de gestão de revistas científicas: uma discussão necessária. Perspectivas em Ciência da Informação, Belo Horizonte, v. 17, n. 1, p. 56-73, 2012.

GUEDES, M. C. Equívocos na publicação científica: algumas considerações. Psicologia USP, São Paulo, v. 22, n. 2, p. 387-398. 2011.

JACOBINA, R. R.; GELMAN, E. A. Juliano Moreira e a Gazeta Médica da Bahia. História, Ciências, Saúde - Manguinhos, Rio de Janeiro, v. 15, n. 4, p. 1077-1097, 2008.

JARDIM, J. B. Adoção, citação e difusão do artigo científico: o que é que se difunde? Psicologia USP, São Paulo, v. 22, n. 2, p. 357-366, 2011.

KRZYZANOWSKI, R. F.; FERREIRA, M. C. G. Avaliação de periódicos científicos e técnicos brasileiros. Ciência da Informação, Brasília, v. 27, n. 2, p. 165-175, 1998.

KUNSCH, M. M. K. Produção científica na Universidade. In: Universidade e comunicação na edificação da sociedade. São Paulo: Loyola, 1992. p. 39-54.

KURAMOTO, H. Acesso livre: um caso de soberania nacional. In: TOUTAIN, L. M. B. B. et al. Para entender a ciência da informação. Salvador: EDUFBA, 2007. p. 145161. 
LEAL, M. C.; COIMBRA JR., C. E. A. Avaliação da pós-graduação no Brasil e seu impacto sobre as revistas científicas nacionais: um alerta. Cadernos de Saúde Pública, Rio de Janeiro, v. 24, n. 11, p. 1-2, 2008.

LEITE, F. C. L.; COSTA, S. M. S. Gestão do conhecimento científico: proposta de um modelo conceitual com base em processos de comunicação científica. Ciência da Informação, Brasília, v. 36, n. 1, p. 92-107, 2007.

. Repositórios institucionais como ferramentas de gestão do conhecimento científico no ambiente acadêmico. Perspectivas em Ciência da Informação, Belo Horizonte, v. 11, n. 2, p. 206-219, 2006.

LOPES, M. I. ; SILVA, E. L. A internet e a busca da informação em comunidades científicas: um estudo focado nos pesquisadores da UFSC. Perspectivas em Ciência da Informação, Belo Horizonte, v.12, n.3, p.21-40, 2007.

MAIA, M. F. S.; CAREGNATO, S. E. Co-autoria como indicador de redes de colaboração científica. Perspectivas em Ciência da Informação, Belo Horizonte, v. 13, n. 2, p. 18-31, 2008.

MIGUEL, K. Los paradigmas de la cobertura mediática de la política ambiental. Intercom: Revista Brasileira de Ciências da Comunicação, São Paulo, v.35, n.1, p. 111-131, 2012.

MIRANDA, D. B.; PEREIRA, M. N. F. O periódico científico como veículo de comunicação: uma revisão de literatura. Ciência da Informação, Brasília, v.25, n.3, p.375-382, 1996.

MONTEIRO, R. et al. Critérios de autoria em trabalhos científicos: um assunto polêmico e delicado. Revista Brasileira de Cirurgia Cardiovascular, São Paulo, v. 19, n. 4, p. 3-8, 2004.

MOUSTAFA, S. P.; MAXIMO, L. F. A produção científica da Anped e da Intercom no GT da Educação e Comunicação. Ciência da Informação, Brasília, v. 32, n. 1, p. 96-101, 2003.

MUELLER, S. P. M. Literatura científica, comunicação científica e ciência da informação. In: TOUTAIN, L. M. B. B. et al. Para entender a ciência da informação. Salvador: EDUFBA, 2007. p. 125-144.

NASCIMENTO, A. R. A. et al. Divulgando a psicologia no rádio: relato de uma experiência. Psicologia: Ciência e Profissão, Brasília, v. 31, n. 4, p. 880-891, 2011.

NEVES, T. M. G. Livre acesso à publicação acadêmica. Ciência da Informação, Brasília, v. 33, n. 3, p. 116-121, 2004.

OLIVEIRA, E. B. Produção científica nacional na área de geociências: análise de critérios de editoração, difusão e indexação em base de dados. Ciência da Informação, Brasília, v. 34, n. 2, p. 34-942, 2005. 
Uso de periódicos científicos eletrônicos por docentes e pós-graduandos do Instituto de Geociências da USP. Ciência da Informação, Brasília, v. 36, n. 3, p. 5966, 2007.

PACKER, A. L.; MENEGHINI, R. Visibilidade da produção científica. In:

POBLACION, D. A.; WITTER, G. P.; SILVA, J. F. M. (Orgs.). Comunicação e produção científica: contexto, indicadores e avaliação. São Paulo: Angellara, 2006. p. 235-260.

PELLIZZON, R. F. et al. Revistas brasileiras publicadoras de artigos científicos em cirurgia. III: análise das instruções aos autores baseadas nos requisitos de Vancouver. Acta Cirúrgica Brasileira, v. 22, n. 6, p. 503-510, 2007.

PINHEIRO, L. V. R. Comunidades científicas e infra-estrutura tecnológica no Brasil para uso de recursos eletrônicos de comunicação e informação na pesquisa.

Ciência da Informação, Brasília, v. 32, n. 3, p. 62-73, 2003.

POBLACION, D. A. et al. Revistas brasileiras publicadoras de artigos científicos em cirurgia.Il- terminologia e atribuições adotadas pelos editores: proposta de organograma do periódico e fluxograma do artigo. Acta Cirúrgica Brasileira, São Paulo, v. 18, n. 6, p. 497-501, 2003.

RIZZINI, C. O jornalismo antes da tipografia. São Paulo: Companhia Editora Nacional, 1977. p. 170-187.

ROSA, S.; LETA, J. Tendências atuais em Educação Física: parte 1: uma análise a partir de periódicos nacionais. Revista Brasileira de Educação Física e Esporte, São Paulo, v. 24, n. 1, p. 121-134, 2010.

RUMMLER, G. Modelagem de um indicador bibliométrico para análise da dispersão de conhecimentos. Ciência da Informação, Brasília, v. 35, n. 1, p. 63-71. 2006.

SANTOS, B. S. A universidade no século XXI: para uma reforma democrática e emancipatória da universidade. In: SANTOS, B. S.; ALMEIDA FILHO, N. A universidade no século XXI: para uma universidade nova. Coimbra: Angellara, 2008. p. 13-106.

SANTOS, V. S. M. Researching documents on the history of Hansen's disease in Brazil. História, Ciências, Saúde-Manguinhos, Rio de Janeiro, v. 10, supl. 1, p. 415-426, 2003.

SCARANO, F. R. Perspectivas das ciências da biodiversidade no Brasil. Scientia Agricola, Piracicaba, v. 64, n. 4, p. 439-447. 2007.

SERRADAS, A. Embedded Librarian: relato de uma experiência na psicologia brasileira. Psicologia USP, São Paulo, v. 22, n. 2, p. 437-443. 2011.

SOUZA, M. P. N. Efeitos das tecnologias da informação na comunicação de pesquisadores da Embrapa. Ciência da Informação, Brasília, v. 32, n. 1, p. 135-43, 2003.

Cad. de Pesq. Interdisc. em Ci-s. Hum-s., Florianópolis, Santa Catarina, ISSN 1984-8951 v.15, n.106, p. 91-116 - jan./jun. 2014 
TARGINO, M. G. Comunicação científica: uma revisão de seus elementos básicos. Informação e Sociedade - Estudos, João Pessoa, v. 10, n. 2, p. 37-8, 2000. TEIXEIRA, R. S. Apresentação. In: BASTIANELLI, L. (Org.) Gazeta Médica da Bahia 1886-1934/1966-1976, por uma Associação de Facultativos. Salvador: Contexto, 2002. p.13

TRISKA, R. ; CAFE, L. Arquivos abertos: sub-projeto da Biblioteca Digital Brasileira. Ciência da Informação, Brasília, v. 30, n. 3, p. 92-96, 2001.

WEITZEL, S. R. Fluxo da informação científica. In: POBLACION, D. A.; WITTER, G. P.; SILVA, J. F. M. (Orgs.). Comunicação e produção científica: contexto, indicadores e avaliação. São Paulo: Angellara, 2006. p. 81-114.

Artigo:

Recebido em: 10/10/2013

Aceito em: 18/07/2014 